\title{
Bubble Retention in Synthetic Sludge: Testing of Alternative
} Gas Retention Apparatus

S. D. Rassat

P. A. Gauglitz

July 1995

Prepared for the U.S. Department of Energy under Contract DE-AC06-76RLO 1830

Pacific Northwest Laboratory Operated for the U.S. Department of Energy by Battelle Memorial Institute 


\title{
DISCLAIMER
}

This report was prepared as an account of work sponsored by an agency of the United States Government. Neither the United States Government nor any agency thereof, nor Battelle Memorial Institute, nor any of their employees, makes any warranty, express or implied, or assumes any legal liability or responsibility for the accuracy, completeness, or usefulness of any information, apparatus, product, or process disclosed, or represents that its use would not infringe privately owned rights. Reference herein to any specific commercial product, process, or service by trade name, trademark, manufacturer, or otherwise does not necessarily constitute or imply its endorsement, recommendation, or favoring by the United States Government or any agency thereof, or Battelle Memorial Institute. The views and opinions of authors expressed herein do not necessarily state or reflect those of the United States Government or any agency thereof.

\author{
PACIFIC NORTHWEST LABORATORY \\ operated by \\ BATTELLE MEMORIAL INSTITUTE \\ for the \\ UNITED STATES DEPARTMENT OF ENERGY \\ under Contract DE-ACO6-76RLO 1830
}

Printed in the United States of America

Available to DOE and DOE contractors from the

Office of Scientific and Technical Information, P.O. Box 62, Oak Ridge, TN 37831; prices available from $(615) 576-8401$.

Available to the public from the National Technical Information Service, U.S. Department of Commerce, 5285 Port Royal Rd., Springfield, VA 22161 


\section{DISCLAIMER}

Portions of this document may be illegible in electronic image products. Images are produced from the best available original document. 


\title{
Bubble Retention in Synthetic Sludge: Testing of Alternative Gas Retention Apparatus
}

\author{
S. D. Rassat \\ P. A. Gauglitz
}

July 1995

Prepared for the U.S. Department of Energy under Contract DE-AC06-76RLO 1830

Pacific Northwest Laboratory

Richland, Washington 99352 



\section{Executive Summary}

Several of the underground storage tanks currently used to store waste at Hanford have been placed on the Flammable Gas Watch List, because the waste is either known or suspected to generate, store, and episodically release flammable gases. The Pacific Northwest Laboratory (PNL) ${ }^{(a)}$ is studying alternative mitigation methods to reduce or eliminate the ability of the waste to retain and episodically release flammable gases. This work is being conducted for Westinghouse Hanford Company as part of the Hydrogen Mitigation project.

The objective of this experimental study is to develop a method to measure gas bubble retention in simulated tank waste and in diluted simulant. The method and apparatus should 1) allow for reasonably rapid experiments, 2) minimize sample disturbance, and 3) provide realistic bubble nucleation and growth. The scope of this experimental study is to build an apparatus for measuring gas retention in simulated waste and to design the apparatus to be compatible with future testing on actual waste.

The approach employed for creating bubbles in sludge involves dissolving a soluble gas into the supernatant liquid at an elevated pressure, recirculating the liquid containing the dissolved gas through the sludge, then reducing the pressure to allow bubbles to nucleate and grow. For the technique to succeed, the gas must be sufficiently soluble in the supernatant liquid. Results have been obtained for ammonia as the soluble gas and SY1-SIM-91A, a chemically representative simulated tank waste. In addition, proof-of-principle experiments were conducted with both ammonia and $\mathrm{CO}_{2}$ as soluble gases and sludge composed of 90 -micron glass beads.

Results show that dissolving soluble gases into the interstitial liquid and then reducing the pressure provides a suitable method of creating bubbles for measuring bubble retention in waste. Because ammonia is very soluble in the simulated wastes, it was determined that reducing the pressure by applying a vacuum to the sample was a very effective and rapid method of nucleating and growing bubbles. Based on the success of this technique, we recommend that bubble retention measurements on real waste samples use the application of a vacuum to nucleate and grow bubbles.

The mechanism of bubble retention was also observed during these tests. For the sludges composed of glass beads, gas was observed to collect in both bubbles that fingered between the particles (dendritic bubbles) and bubbles that displaced the particles (both small round bubbles and large bubbles that fractured the sludge). In contrast, only small round bubbles that displaced particles were observed in the SY1-SIM-91A chemical simulant. It was also observed that gas bubbles did not readily coalesce in SY1-SIM-91A, presumably due to small particles armoring these bubbles.

(a) Pacific Northwest Laboratory is operated by Battelle Memorial Institute for the U.S. Department of Energy under Contract DE-AC06-76RLO 1830. 



\section{Contents}

Executive Summary $\ldots \ldots \ldots \ldots \ldots \ldots \ldots \ldots \ldots \ldots \ldots \ldots \ldots$ iii

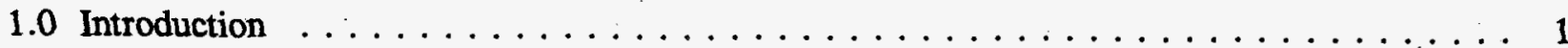

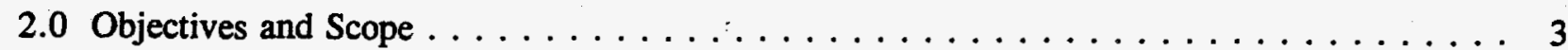

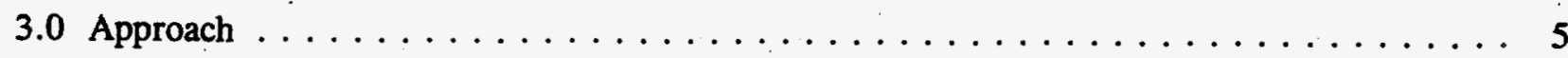

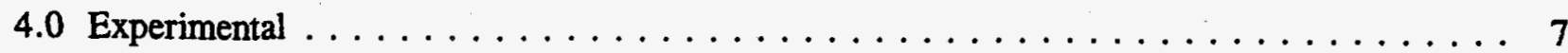

4.1 Apparatus Design $\ldots \ldots \ldots \ldots \ldots \ldots \ldots \ldots \ldots \ldots \ldots \ldots \ldots \ldots \ldots \ldots$

4.2 Simulated Waste Materials $\ldots \ldots \ldots \ldots \ldots \ldots \ldots \ldots \ldots$

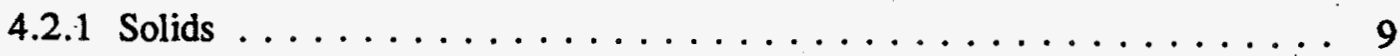

4.2 .2 Liquids $\ldots \ldots \ldots \ldots \ldots \ldots \ldots \ldots \ldots \ldots \ldots \ldots \ldots \ldots \ldots \ldots$

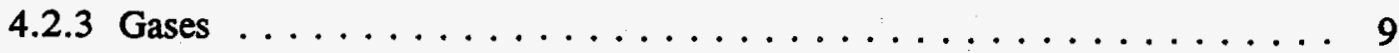

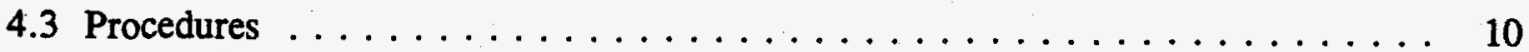

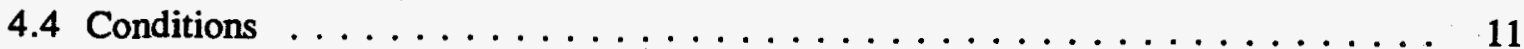

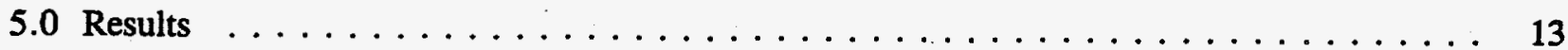

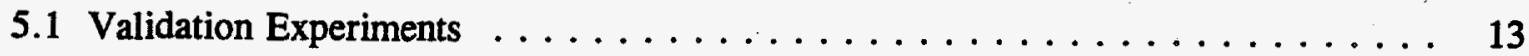

5.2 Ammonia Gas with Simulated Sludge . . . . . . . . . . . . . 15

5.3 Ammonia Gas with Chemical Simulant $\ldots \ldots \ldots \ldots \ldots$

6.0 Discussion and Future Work $\ldots \ldots \ldots \ldots \ldots \ldots \ldots$

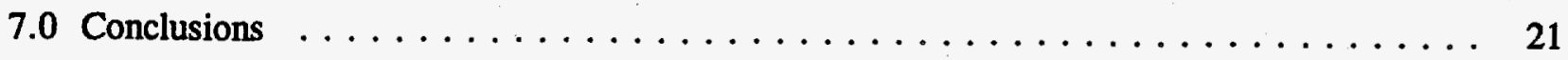

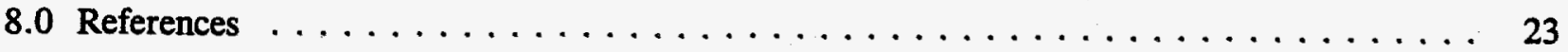

Appendix: Detailed Experimental Procedures $\ldots \ldots \ldots \ldots \ldots \ldots \ldots \ldots \ldots \ldots \ldots$.1 


\section{Figures}

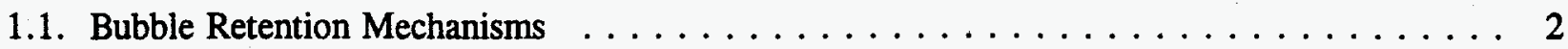

3.1. Simplified Schematic of the Recirculating Fluid Bubble Retention Experiment $\ldots \ldots \ldots$

4.1. Detailed Schematic of the Recirculating Fluid Bubble Retention Apparatus . . . . . . . . 7

5.1. Effect of Recirculation Duration on Bubble Retention Dynamics for Glass Beads in Carbonated Water $\ldots \ldots \ldots \ldots \ldots \ldots \ldots \ldots \ldots \ldots$

5.2. Effect of Recirculation Duration on Change in Supernatant Liquid Height Relative to Change in Sludge Level for Glass Beads in Carbonated Water . . . . . . . . . 14

5.3. Comparison of Overall Bubble Retention by Vacuum Depressurization for Glass Beads in Two Supernatant Liquids, Water and Ammonium Hydroxide . . . . . . 15

5.4. Comparison of Apparent Bubble Retention Mechanism by Glass Particle/Ammonium Hydroxide and Glass Particle/Carbonated Water Simulated Wastes . . . . . . . . . . . .

5.5. Effect of Added Ammonia Gas on the Overall Gas Retention in a SY1-SIM-91A

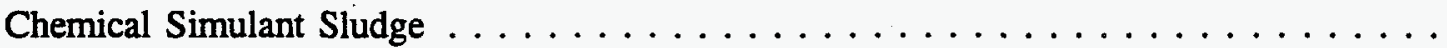

5.6. Comparison of Apparent Bubble Retention Mechanism by Glass Particle/Ammonium Hydroxide and SY1-SIM-91A Chemical Simulant/Ammonia Simulated Wastes

\section{Tables}

4.1. SY1-SIM-91A Sludge Simulant Composition $\ldots \ldots \ldots \ldots \ldots \ldots \ldots$

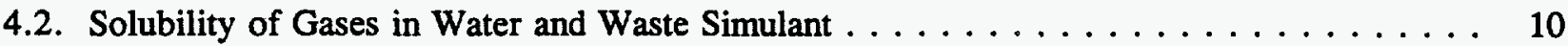




\subsection{Introduction}

Several of the underground storage tanks currently used to store waste at Hanford have been placed on the Flammable Gas Watch List because the waste is either known or suspected to generate, store, and episodically release flammable gases. Episodic releases of flammable gases from waste tanks is an important safety concern. While each episodic release is unique, the underlying physical mechanisms governing retention of gas within the waste and the sudden release of this gas interrelate the separate events. In some of the observed cases, tank waste separates into an upper liquid layer, termed the "convective" layer, and a lower layer of settled solid particles, or sludge, termed the "nonconvective" layer (Allemann et al. 1990a, 1990b, 1991, 1993). Much of the generated gas collects as bubbles in the lower sludge. The formation of bubbles, their retention, and their release are central to understanding and predicting the volume and rate of gas released during a release event.

To store the waste safely, the retention of flammable gases must be minimized, and the conditions resulting in sudden releases of flammable gases in potentially hazardous quantities must be avoided (Stewart et al. 1994). Dilution of tank waste is currently thought to provide a passive mitigation of the problems associated with the large flammable gas releases. Waste dilution will be required to meet retrieval and transport requirements (Rieck 1994; Hudson et al. 1995). Because of this, an understanding of the effects of dilution on gas retention behavior is necessary to anticipate and model potential safety and operational issues associated with downstream processing.

Previous laboratory efforts have focused on obtaining measurements of physical and rheological properties that are related to the waste's ability to retain gas. However, very few laboratory data exist on the amount of gas a waste can retain. Essentially no data exist on the ability of diluted waste to retain gas bubbles, and existing data are not sufficient to prove that dilution will mitigate the retention and episodic release of flammable gases from waste tanks (Stewart et al. 1994). Accordingly, this work focused on developing an apparatus for measuring the ability of simulated sludge to retain gas bubbles.

Bubbles held in settled sludge in the lower part of a waste tank account for most of the gas retained by a waste, and this retention of bubbles therefore plays a pivotal role in gas release events. For a sludge to retain bubbles, the sludge must contribute forces sufficiently strong to resist the buoyant force that is causing the bubble to rise. Gauglitz et al. (1994) discussed bubble retention mechanisms in waste, which are generally classified into one of the five mechanisms shown in Figure 1.1. (a) Depending on the physical properties of the sludge and the depth of the retained bubbles, the bubbles have been observed to displace the sludge (round bubbles) and be retained by the yield stress of the sludge or to finger between the sludge particles (dendritic bubbles) and be retained by capillary forces.

Previous studies of bubble retention used a variety of techniques to create retained bubbles within simulated sludges. One recent approach involved dissolving a soluble gas into the supernatant liquid at an elevated pressure, mixing the liquid containing dissolved gas through the sludge by shaking the

(a) N. G. McDuffie (WHC) summarized these mechanisms in a recent presentation entitled Flammable Gas Generation, Retention, and Release in High-Level Waste Tanks: Physical and Chemical Models. 1994. Presented at Hanford Technical Exchange Program, "The Hanford High-Level Waste Tank Remediation Program-A Strategic Re-Evaluation." 
sample, then reducing the pressure to allow bubbles to nucleate and grow. (a) P. R. Bredt has proposed exposing a waste sample to a high radiation dose to accelerate gas generation in sludges that will retain

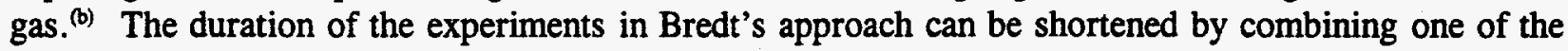
experimental techniques described in this report (see Section 6.0). In previous studies of gas-bubble retention in simulated waste, carbon dioxide $\left(\mathrm{CO}_{2}\right)$ was selected as the soluble gas for the initial proof-ofprinciple experiments. The approach described in this report extends this technique. Other techniques employed to create retained bubbles include mixing yeast with sugar to create $\mathrm{CO}_{2}$ bubbles (Gauglitz et al. 1994; Hall 1993). While this method provides uniform bubble nucleation and growth, sugar and yeast are not suitable for studies with real waste. Sparging gas into simulated waste has also been used to observe bubble attachment to solid particles (Bryan et al. 1991, 1992, 1993), but this technique is not well suited for creating retained bubbles in settled sludge, because sparging the bubbles stirs the sludge.

Section 2 of this report presents the objectives and scope of this experimental study. The approach for creating retained bubbles and measuring bubble retention is then described in Section 3 , followed by a detailed description of the apparatus, materials used, and procedures for conducting the experiments in Section 4. The results are then presented in Section 5 and discussed in Section 6 with an emphasis on the suitability of this approach for monitoring gas-bubble retention. Conclusions can be found in Section 7, and the detailed experimental procedure is contained in the appendix.

Yield Stress

Retention

(Viscous)

Armored Bubbles

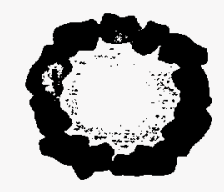

Bubble Attachment

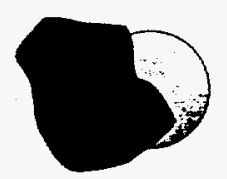

Aggregates

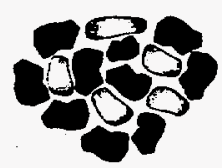

Capillary

Forces

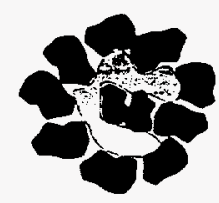

Figure 1.1. Bubble Retention Mechanisms

(a) Gauglitz, P. A., and S. D. Rassat. April 1995. Experimental Methods to Generate Retained Bubbles in Simulated Sludges. PNL letter report WTSFG95.10 to WHC, Richland, Washington.

(b) Bredt, P. R. 1994. Test Plan for Tank 241-SY-101 Gas Retention Testing (101SY-D-TP Rev. 0). Bredt (PNL) proposed creating retained bubbles by exposing real or simulated waste to radiation, similar to Bryan and Pederson's (1994) method of generating gas in simulated waste. Gas is generated by waste decomposition, and generation rate is controlled by adjusting radiation dosage. This experiment may take ten days or longer, so a more rapid experiment such as the one described in this report will be valuable. 


\subsection{Objectives and Scope}

The specific objective of this experimental study was to develop a method to measure gas bubble retention in simulated tank waste and in diluted simulant. The apparatus allowed for the following:

- Experiments performed rapidly (one or two elapsed days/sample)

- Minimal sample disturbance (after dilution)

- Realistic bubble growth and nucleation

- Uniform distribution of bubbles.

The scope of this experimental study was to build an apparatus for measuring gas retention in simulated waste and to design the apparatus to be compatible with future testing on actual waste. We also sought to improve the method and apparatus based on the results of these initial tests. The initial proofof-principle experiments used $\mathrm{CO}_{2}$ gas to generate gas bubbles and fine silica particles (glass beads) in water as a waste simulant. Because the ultimate goal is to study actual waste, experiments were also conducted with ammonia as the gas and SY1-SIM-91A waste simulant (described in Section 4.2) as chemically representative of tank waste. These ammonia/SY1-SIM-91A experiments should encompass most of the experimental difficulties that will be encountered with actual waste studies. 


\subsection{Approach}

Within a fluid, bubbles tend to rise due to gravity. For a waste sludge to retain these bubbles, it must be sufficiently strong to overcome this buoyant force. For a specific waste sample, the volume of retained gas bubbles can be determined from measurements of the height of the waste level with and without gas bubbles. The volume of the retained gas should give a direct indication of the ability of a waste to retain gas bubbles.

For this study, the approach for creating bubbles in sludge involves dissolving a soluble gas into the supernatant liquid at an elevated pressure, recirculating the liquid containing the dissolved gas through the sludge, then reducing the pressure to allow bubbles to nucleate and grow. A simplified schematic diagram of this experimental approach is depicted in Figure 3.1. For the technique to succeed, the gas must be sufficiently soluble in the supernatant liquid. A number of gases fit this criterion, including ammonia $\left(\mathrm{NH}_{3}\right)$, nitrous oxide $\left(\mathrm{N}_{2} \mathrm{O}\right)$, and $\mathrm{CO}_{2}{ }^{(a)}$ While $\mathrm{CO}_{2}$ is sufficiently soluble in water, chemical reactions between $\mathrm{CO}_{2}$ and alkaline waste make $\mathrm{CO}_{2}$ undesirable with real waste. Nitrous oxide is a third less soluble in water than $\mathrm{CO}_{2}$ and is a potential choice for studies with real waste. Some perfluorocarbons are more soluble in aqueous solutions than $\mathrm{CO}_{2}$, but these gases are known to decompose in highly alkaline solutions, so this class of gases is not suitable for real waste studies. Because of its high solubility in chemical simulants (Norton and Pederson 1994) and its expected similar behavior in real waste, ammonia is perhaps the best choice for use with real waste.

The volume of gas bubbles created by any technique can be increased by applying a vacuum to the simulants. The applied vacuum causes additional gas to evolve from the solution and contributes to the growth of existing bubbles by expansion of the gas. The application of a vacuum should result in less gas needing to be dissolved in the waste to provide sufficient bubble nucleation and growth.

(a) In a recent letter report entitled Experimental Methods to Generate Retained Bubbles in Simulated Sludges (April 1995), Gauglitz and Rassat discussed these gases and reported Henry's constants taken from the literature. Pacific Northwest Laboratory, Richland, Washington. 


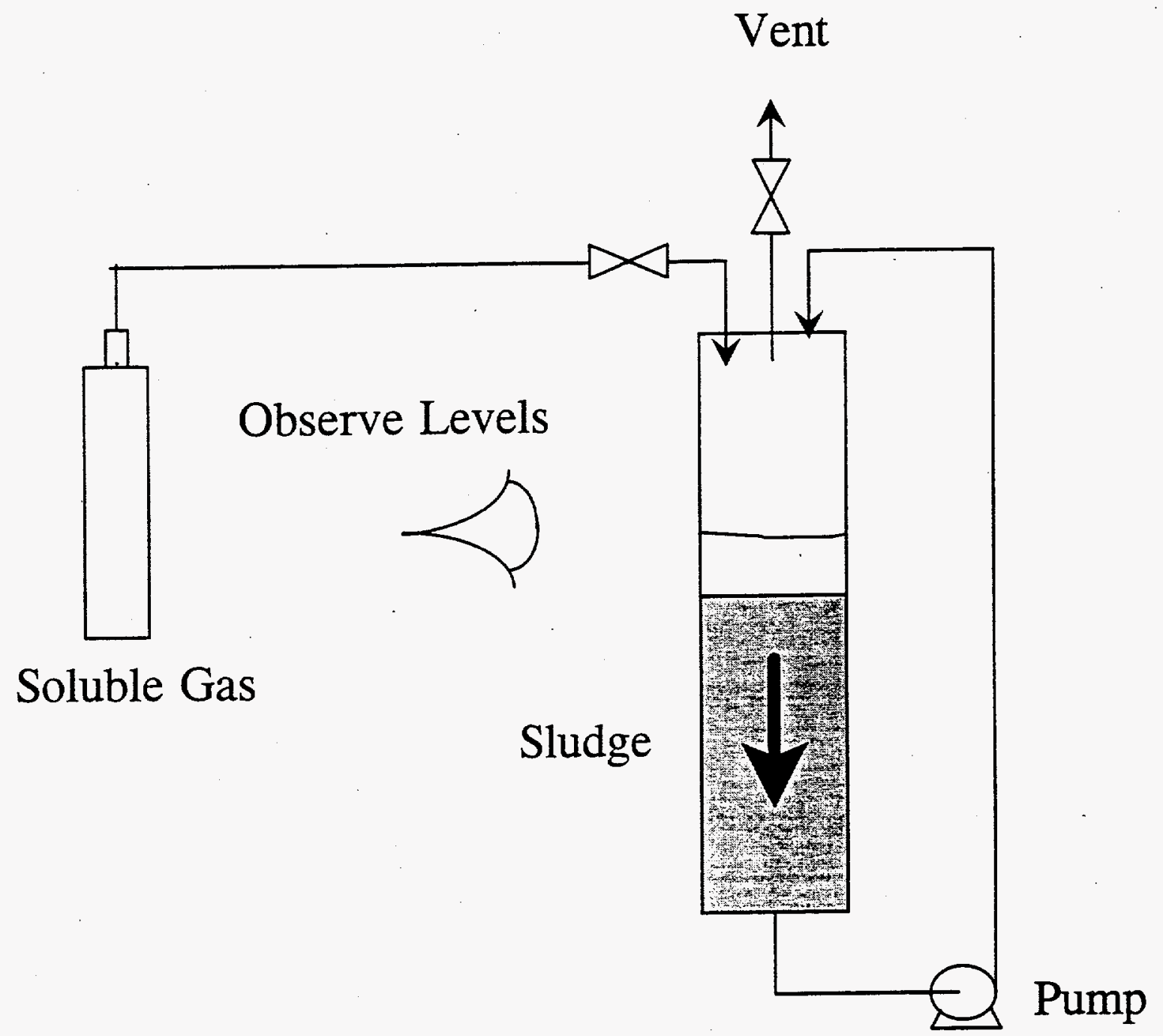

Figure 3.1. Simplified Schematic of the Recirculating Fluid Bubble Retention Experiment 


\subsection{Experimental}

Developing an experimental scheme to study bubble retention in simulated wastes that can also be applied to studies with real wastes involves several factors: designing the apparatus with particular concern for the materials of construction; identifying simulated waste materials for proof-of-concept experiments leading to actual waste studies; developing experimental procedures; and identifying key operating conditions that must be investigated in scoping studies.

\subsection{Apparatus Design}

Figure 4.1 is a detailed design of the bubble retention apparatus with recirculating fluid that consists of four functional units: a clear test chamber for observing gas retention by the sludge, a recirculation pump and associated plumbing, a venting system with an optional exhaust to a vacuum system, and a gas feed system that includes a cylinder of compressed gas equipped with a regulator.

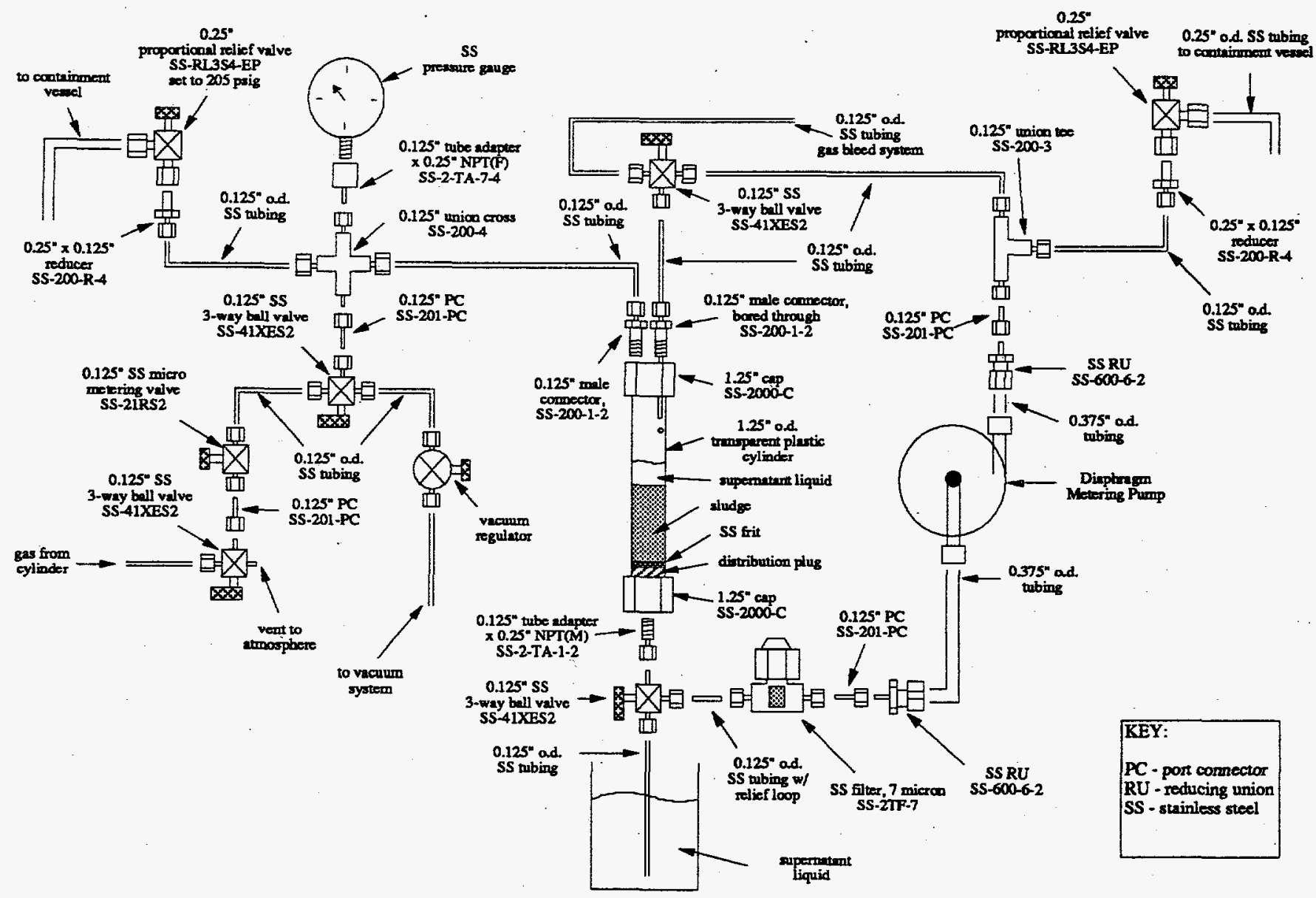

Figure 4.1. Detailed Schematic of the Recirculating Fluid Bubble Retention Apparatus 
The apparatus was designed to be adapted to study bubble retention in real waste with only minor modifications. As a consequence, the physical dimensions are small, and materials of construction are limited. The size limitations (a cylinder approximately $0.45 \mathrm{~m}$ long and $0.33 \mathrm{~m}$ in diameter) result from the anticipated need to conduct experiments in a hot cell with an airlock passage of fixed dimension. Physical and chemical compatibility of wastes, the radiation environment, and the apparatus drive the choice of apparatus materials. As shown in Fig. 4.1, most fittings, tubing, valves, and the pressure gauge in the apparatus are constructed of type 316 stainless steel (SS). Specific Swagelok fittings and valves are identified in the drawing.

The choice of material for the test chamber is particularly critical and somewhat limited. The chamber must be transparent, able to withstand continuous operating pressures to $5 \times 10^{5} \mathrm{~Pa} \mathrm{(60} \mathrm{psig),}$ resistant to chemical interaction with the sludge and supernatant liquid, and able to withstand radiation from the waste sample and background radiation in the hot cell. Polycarbonate (Lexan) has good clarity and meets the pressure requirement, but it is unacceptable because it is incompatible with ammonia and ammonium hydroxide. However, a polycarbonate retention column was used for scoping experiments with pressurized $\mathrm{CO}_{2}$ gas, water, and glass particles. Plexiglass (acrylic) has good clarity and is compatible with ammonium hydroxide, chemical simulant SY1-SIM-91A, and ammonia. Although plexiglass is estimated to be safe to considerably higher pressures than were used in these preliminary experiments (up to $1.7 \times 10^{5} \mathrm{~Pa}$ with ammonia), this plastic is more shatter-prone than polycarbonate, and its safety limits should be further investigated before conducting experiments above $2.0 \times 10^{5} \mathrm{~Pa}$ (15 psig) with either chemical simulant or real waste. Other plastics considered for the test chamber include clear rigid polyvinyl chloride (PVC), polysulfone, and polymethylpentene. PVC is readily available in pipe sizes, has moderate transparency, and is chemically compatible, but it is not recommended for gas service. Polysulfone appears less chemically resistant, is less transparent, and is more difficult to obtain than the other plastics. Polymethylpentene has good chemical compatibility with chemical simulants and ammonia compounds and has excellent transparency, but it is difficult to acquire in appropriate tube dimensions.

The pump used in these preliminary studies was a diaphragm metering pump (Pulsatron Series E Plus) with a maximum liquid flow rate of $13 \mathrm{~mL} / \mathrm{min}$., a maximum operating pressure of $1.8 \times 10^{6} \mathrm{~Pa}$ (250 psig), and a maximum fluid temperature of $87^{\circ} \mathrm{C}$. The pump wetted parts (Teflon PTFE, Hypalon, and ceramic) appear chemically compatible with chemical simulant SY1-SIM-91A and ammonium hydroxide and are, therefore, expected to be chemically compatible with real waste. However, this specific pump may not be suitable for real waste studies, because the hot-cell radiation environment may disrupt the integrated pump electronics. Before beginning the recirculating fluid bubble retention experiments on real wastes in a hot cell, the pump issue must be revisited.

\subsection{Simulated Waste Materials}

The simulated waste materials consist of three components: solid, liquid, and dissolved gas. The initial waste sludge (or settled slurry) consists of solid particulate settled in a liquid (or liquid with dissolved gas). In the experiments described here, sufficient liquid was introduced into the retention column to form a layer of supernatant liquid $(\sim 2 \mathrm{~cm})$ on top of the sludge column $(\sim 15 \mathrm{~cm})$. A range of waste sludge components were used in these experiments. 


\subsubsection{Solids}

Two types of sludge solids were used. In proof-of-principle experiments with a variety of liquids and gases, 90-micron nominal diameter glass beads were employed. Other experiments were conducted with chemical simulant SY1-SIM-91A (Bryan and Pederson 1994), a concentrated mixture of $\mathrm{NaOH}$ and sodium salts that forms a thick sludge and is chemically representative of the sludge in the waste tanks. The composition of the simulant is presented in Table 4.1. The SY1-SIM-91A simulant containing the trisodium salt of ethylenediaminetetraacetic acid is a saturated salt solution containing precipitated salt crystals. The simulant used in these experiments was centrifuged to separate the precipitated salt (and interstitial liquid) from the supernatant liquid.

\subsubsection{Liquids}

In the chemical simulant experiments, the centrifuged supernatant liquid fraction was used in conjunction with the interstitial liquid retained in the centrifuged solids. In the proof-of-concept experiments with glass particles, the liquid was either deionized water or ammonium hydroxide (VWR Scientific, 28-30 wt\% as ammonia).

\subsubsection{Gases}

A number of gases, such as ammonia $\left(\mathrm{NH}_{3}\right)$, nitrous oxide $\left(\mathrm{N}_{2} \mathrm{O}\right)$, and $\left(\mathrm{CO}_{2}\right)$, can be adequately dissolved in liquids. Table 4.2 gives the solubility of these gases in water and the solubility of $\mathrm{NH}_{3}$ in chemical simulant. Ammonia is the most soluble of these gases and is about two orders of magnitude more soluble than $\mathrm{CO}_{2}$ in water. As a result of its relatively high solubility, and because it is a gas found in real waste tanks, it is considered the most suitable test gas for bubble retention studies with chemical simulant. Anhydrous ammonia ( $>99.99 \%$ ) was used in the chemical simulant tests. For proof-ofconcept experiments with glass-bead sludges, both $\mathrm{CO}_{2}$ and liquid ammonium hydroxide (ammonia in water) were used. Experimentation with ammonia is more difficult than with $\mathrm{CO}_{2}$ because of safety considerations (flammable and toxic gas).

Table 4.1. SY1-SIM-91A Sludge Simulant Composition

$\underline{\mathrm{Wt} \%}$

31.7

14.3

20.3

5.9

4.1

16.3

7.4

Chemical

$\mathrm{H}_{2} \mathrm{O}$

$\mathrm{NaNO}_{2}$

$\mathrm{NaNO}_{3}$

$\mathrm{NaOH}$

$\mathrm{Na}_{2} \mathrm{CO}_{3}$

$\mathrm{NaAl}(\mathrm{OH})_{4}$

$\mathrm{Na}_{3} \mathrm{HEDTA}$
$\underline{M(\mathrm{~mol} / \mathrm{L})}$

3.2

3.7

2.3

0.6

2.2

0.3

\section{Common Name}

Water

Sodium nitrite

Sodium nitrate

Sodium hydroxide

Sodium carbonate

Sodium aluminate

Ethylene diamine tetraacetic acid, trisodium salt 
Table 4.2. Solubility of Gases in Water and Waste Simulant

\begin{tabular}{||l|l|l|l||}
\hline Gas & $\begin{array}{l}\text { Henry's Constant } \\
\text { (atm/moles/liter) } \\
\text { water @ 20 }\end{array}$ & $\begin{array}{l}\text { Henry's Constant } \\
\text { (atm/moles/liter) } \\
\text { SY1-SIM-91A }\end{array}$ & Comments \\
\hline $\mathrm{NH}_{3}$ & $0.013^{(\mathrm{a})}$ & $\begin{array}{l}0.122^{(\mathrm{a})} @ 20^{\circ} \mathrm{C} \\
0.252^{(\mathrm{a})} @ 50^{\circ} \mathrm{C}\end{array}$ & $\begin{array}{l}\text { Combustible (LEL=15\%) } \\
\text { Hazardous (IDLH=500 ppm) }\end{array}$ \\
\hline $\mathrm{N}_{2} \mathrm{O}$ & $36^{(\text {b) }}$ & & Oxidizer \\
\hline $\mathrm{CO}_{2}$ & $22^{(\mathrm{c})}$ & & Will react with waste \\
\hline \hline
\end{tabular}

(a) Norton and Pederson (1994), assuming $1 \mathrm{~kg}$ water $\approx 1$ liter.

(b) Perry (1950).

(c) Yaws et al. (1991).

Nitrous oxide was not used in these experiments but remains a potential candidate for actual waste studies. It is potentially advantageous in that it, like $\mathrm{NH}_{3}$, is a gas found in waste tanks. However, it is an oxidizer and must be used safely with naturally occurring $\mathrm{NH}_{3}$ and hydrogen gases in real waste samples. Also, the more limited solubility of $\mathrm{N}_{2} \mathrm{O}$, especially when the high salinity of a waste further reduces the solubility (Norton and Pederson 1994), requires a higher gas pressure to dissolve sufficient gas into the sludge.

\subsection{Procedures}

Two different bubble retention experiments were conducted. In the more complex experiments, a partially soluble gas was dissolved in the sludge by fluid recirculation. A sludge and supernatant liquid are placed in the sample column, a partially soluble gas of choice is delivered from a high-pressure cylinder into the top of the sample holder, the gas is mixed into the sludge/slurry by recirculating the supernatant liquid through the sludge until the sludge is uniformly mixed with supernatant containing dissolved gas, and the retention column is depressurized to nucleate and grow bubbles in the sludge. Details of this experimental procedure are given in the appendix (Section A.1). In some of the added-gas experiments, depressurization to atmospheric pressure was insufficient to obtain the desired bubble growth, so vacuum depressurization was applied to achieve nucleation and growth.

A simpler experiment was also conducted by applying a vacuum to nucleate and grow bubbles from the naturally existing gas within the sludge. In this experiment, the full features of the apparatus shown in Figure 4.1 are not required. The simpler experiment entails placing the sludge and supernatant liquid in the bubble retention column and evacuating the headspace of the chamber to nucleate and grow bubbles. A detailed description of this procedure is given in the appendix (Section A.2).

In all of the experimental approaches, the bubble retention mechanisms are identified by observing the bubbles in the sludge layer, and the gas retention is quantified by monitoring the sludge and supernatant liquid levels during (and after) depressurization. 


\subsection{Conditions}

Scoping experiments with a simulated waste of glass particles, water, and $\mathrm{CO}_{2}$ gas were conducted to determine acceptable values for three operating parameters: 1) initial (equilibrium) $\mathrm{CO}_{2}$ pressure; 2) sample depressurization rate; and 3) duration of recirculation. The first two parameters were previously identified using a proof-of-concept bubble retention apparatus described Gauglitz and Rassat. ${ }^{\text {(a) }}$ In this earlier work, conducted exclusively with $\mathrm{CO}_{2}$ as the soluble gas, a pseudo-equilibrium

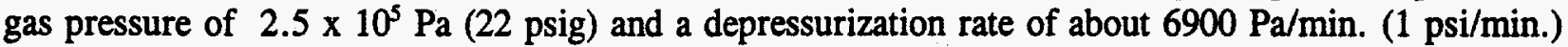
gave good sludge growth in a reasonable period of time (30-40 min.). Similar operating conditions were found to give reasonable results with the recirculation apparatus described here. Therefore, the initial recirculating fluid bubble retention experiments focused on identifying the duration of recirculation needed to achieve a uniform equilibrium concentration of $\mathrm{CO}_{2}$ gas solubilized in the water/90 micron glass bead sludge. The recirculation duration was varied from 30-360 minutes with a recirculation rate of about $2 \mathrm{~mL} / \mathrm{min}$.

Similar scoping experiments with ammonia as the gas and SY1-SIM-91A as a chemically representative simulant for tank waste were initiated. Ideal operating conditions have not been identified, although conditions necessary to achieve reasonable data were obtained: a minimum 240 minute recirculation at a rate of $\sim 2 \mathrm{~mL} / \mathrm{min}$. and an ammonia gas pressure of $1.7 \times 10^{5} \mathrm{~Pa}(10 \mathrm{psig})$, and depressurization to atmospheric pressure at a rate of $\sim 6900 \mathrm{~Pa} / \mathrm{min}$. (1 psi/min.) followed by vacuum depressurization at a rate of $\sim 1700 \mathrm{~Pa} / \mathrm{min}$. ( $0.5 \mathrm{in}$. mercury $[\mathrm{Hg}] / \mathrm{min}$.). The vacuum depressurization rate may be too slow and should be investigated further. Also, the 240-minute recirculation provided sufficient solubilized $\mathrm{NH}_{3}$ to give good bubble growth, but the duration was insufficient to reach an equilibrium condition.

(a) Gauglitz, P. A., and S. D. Rassat. April 1995. Experimental Methods to Generate Retained Bubbles in Simulated Sludges. PNL letter report WTSFG95.10 to WHC, Richland, Washington. 



\subsection{Results}

Gas retention experiments were conducted in the recirculating fluid bubble retention apparatus using several simulated wastes. Experiments with glass beads, water, and $\mathrm{CO}_{2}$ were used to validate the experimental approach and to gain experience with the apparatus, and then experiments with ammonia as the dissolved gas were performed. As actual tank waste gas retention behavior is the driver for this work, experiments were conducted using a chemical simulant waste which mimics the chemical and, to a certain extent, the physical characteristics of real waste. Gas retention tests were performed using both the natural sample gas and, separately, by addition of anhydrous ammonia.

\subsection{Validation Experiments}

Several experiments with simulated wastes consisting of 90 -micron-diameter glass particles, water, and dissolved $\mathrm{CO}_{2}$ gas were conducted to validate the recirculating fluid gas retention experimental technique. Figure 5.1 shows the effect of the duration of recirculation on the change in supernatant liquid level, or overall gas retention, as a function of time. In each of the data sets shown in Figure 5.1, the $\mathrm{CO}_{2}$ pressure was maintained at $2.4 \times 10^{5} \mathrm{~Pa}(20 \mathrm{psig})$ throughout the recirculation period, and the sample was depressurized to atmospheric pressure at the rate of $6900 \mathrm{~Pa} / \mathrm{min}$. (1 psi/min.). The elapsed time is measured from the start of depressurization, and sudden decreases in the liquid height represent gas release from the sludge. Figure 5.1 shows comparable level growth and maximum values for recirculation periods of 120,240 , and 360 minutes. The variability of the maximum liquid level rise in these experiments $(2.8-4.2 \mathrm{~cm})$ may be attributed to differences in the settled sludge strengths, and the maximum growth does not appear to correlate with recirculation duration. For example, the maximum sludge growth in the 360-minute recirculation experiment $(2.8 \mathrm{~cm})$ was less than that observed in the 120 minute $(3.2 \mathrm{~cm})$ and 240 -minute $(4.2 \mathrm{~cm})$ tests. With a 30 -minute recirculation period, Figure 5.1 shows that insufficient $\mathrm{CO}_{2}$ was dissolved into the water. A maximum liquid level rise of $0.6 \mathrm{~cm}$ was observed, and no gas was released from the simulated waste. Based on these studies, a 120-minute recirculation duration was determined to be adequate for the 90 -micron glass bead/water $/ \mathrm{CO}_{2}$ simulated waste system, and the equilibrium $\mathrm{CO}_{2}$ pressure $\left(2.4 \times 10^{5} \mathrm{~Pa}\right)$ and depressurization rate $(6900 \mathrm{~Pa} / \mathrm{min}$.) were confirmed to be suitable.

In these recirculation-duration experiments, both the sludge heights and supernatant liquid levels were monitored as a function of time during the bubble growth. Figure 5.2 shows the change in sludge height as a function of the liquid level rise for the four recirculation-duration experiments. This figure highlights information on both the magnitude and mechanism of bubble retention in the sludges. Dendritic bubbles, which often form in the lower regions of the sludge, finger between particles and affect only the supernatant liquid level. Large round bubbles and fracture bubbles, which sometime form at the top of a percolation zone between the round and dendritic bubble regimes, displace both solid particulate and liquid. Thus a change in liquid level without any change in sludge height is indicative of gas retention by dendritic bubbles, and where the liquid level rises at the same rate as the sludge level, gas is retained as round or fracture bubbles. The data of Figure 5.2 suggest that the predominant mechanism of bubble retention in these sludges is by round and/or fracture bubbles. The mechanism of bubble retention also appears to be independent of the duration of recirculation, because all data points align near a line of slope one. 


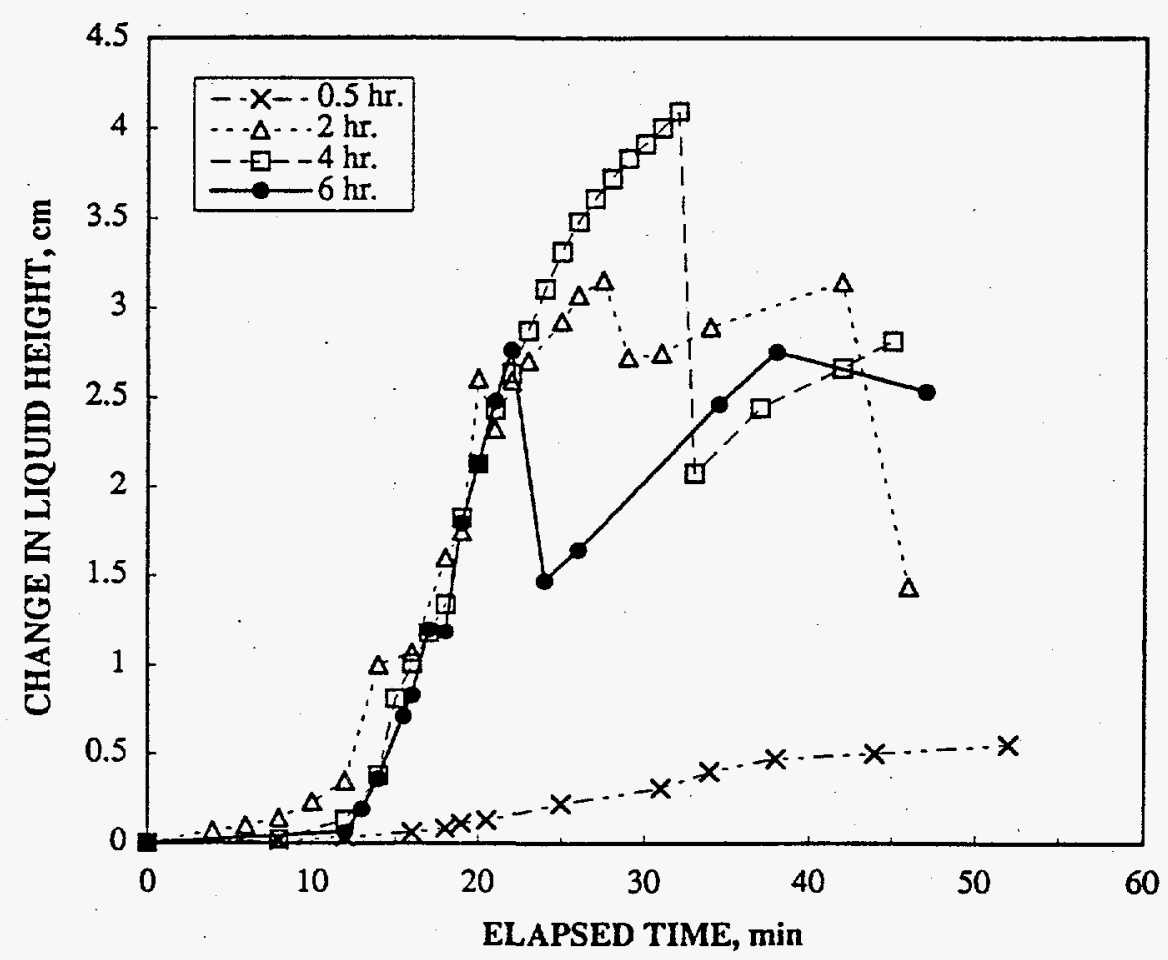

Figure 5.1. Effect of Recirculation Duration on Bubble Retention Dynamics for Glass Beads in Carbonated Water

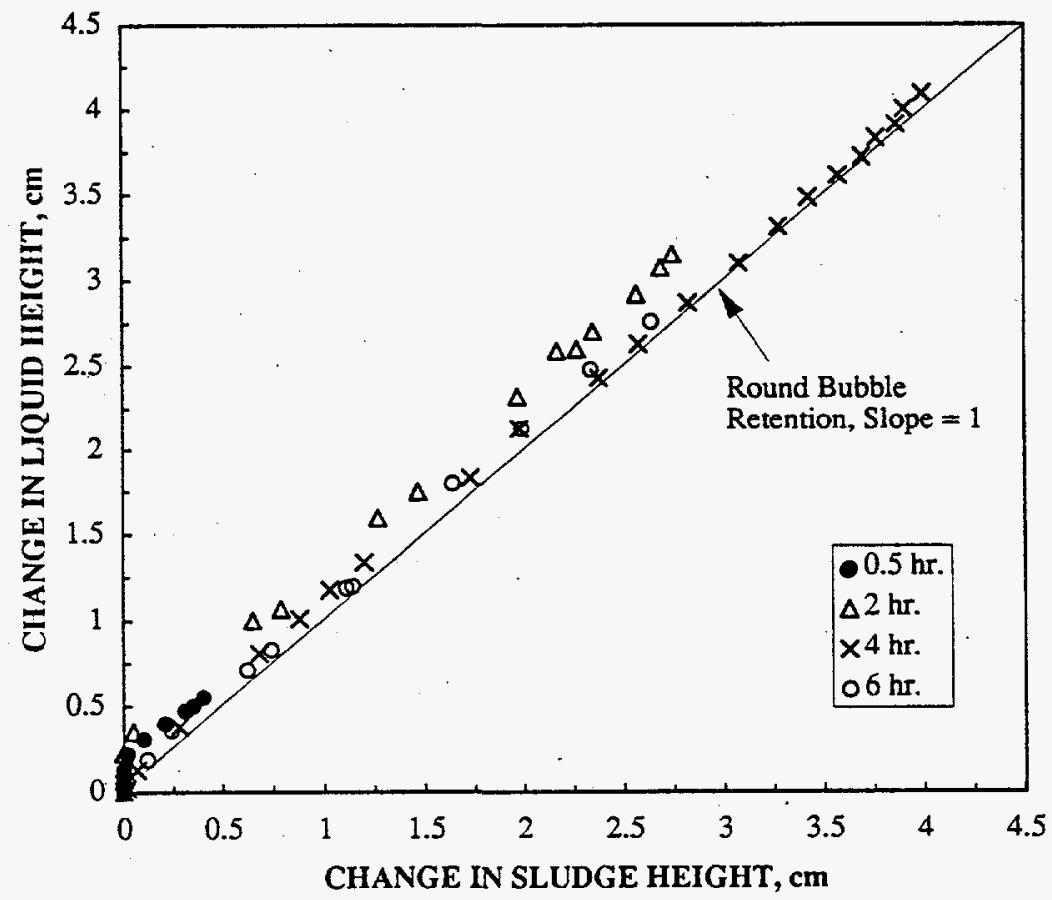

Figure 5.2. Effect of Recirculation Duration on Change in Supernatant Liquid Height Relative to Change in Sludge Level for Glass Beads in Carbonated Water 


\subsection{Ammonia Gas with Simulated Sludge}

To investigate ammonia as the soluble gas for bubble retention experiments in actual and chemical simulant sludges, initial scoping experiments were conducted with a sludge consisting of 90-microndiameter (nominal) glass beads and ammonium hydroxide. In these experiments, no additional gas was introduced into the sample. The dissolved ammonia in the ammonium hydroxide (ammonia in water) was induced to nucleate and grow as bubbles by applying a vacuum to the bubble retention test chamber. Figure 5.3 shows the overall gas retention, represented as liquid level rise, as a function of applied vacuum for the glass particle/ammonium hydroxide sludge. At a pressure of $\sim 5.6 \times 10^{4} \mathrm{~Pa}$ (13.5 in. $\mathrm{Hg}$ vacuum) the sludge column attained its maximum growth $(4.3 \mathrm{~cm})$ prior to gas release. At still lower pressures bubbles grew quickly, and gas release events occurred frequently and uncontrollably. For reference, Figure 5.3 shows the results of an analogous experiment conducted with 90-micron glass particles in water. The maximum growth $(1.1 \mathrm{~cm})$ in the water-based sludge occurred at the lowest pressure achievable with the laboratory house vacuum system $\left(2.2 \times 10^{4} \mathrm{~Pa}\right.$ [23.5 in. $\mathrm{Hg}$ vacuum]). Growth in the water-based sludge is likely due to a combination of dissolution of a small amount of naturally occurring dissolved gases and water vapor. At $\sim 5.6 \times 10^{4} \mathrm{~Pa}$ (13.5 in. $\mathrm{Hg}$ vacuum), Figure 5.3 shows that the supernatant liquid level had risen only $0.2-0.3 \mathrm{~cm}$ for this water/glass-particle system. Thus, the large level rise in the ammonium hydroxide/glass bead system was due predominantly to the growth and retention of ammonia gas bubbles.

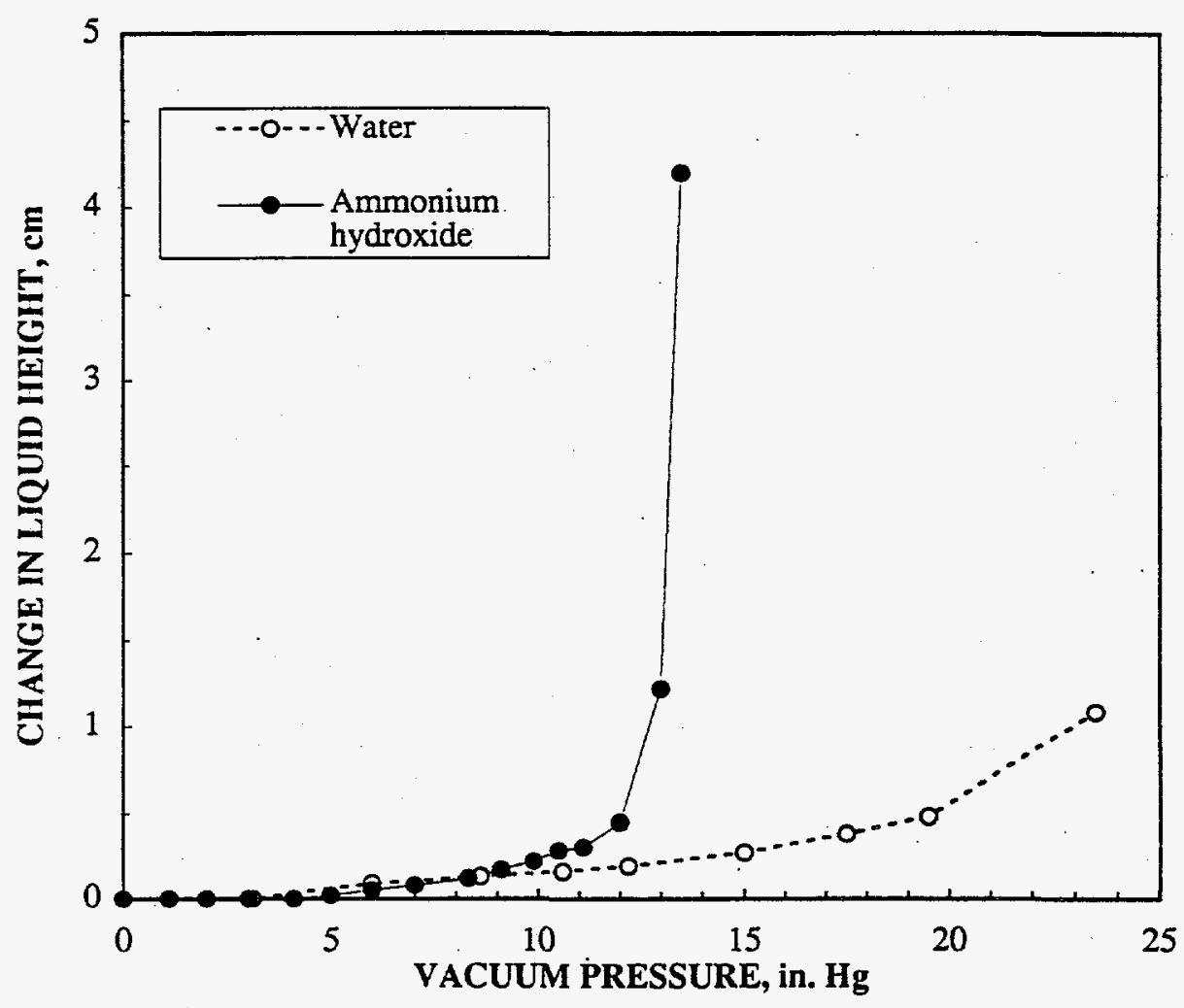

Figure 5.3. Comparison of Overall Bubble Retention by Vacuum Depressurization for Glass Beads in Two Supernatant Liquids: Water and Ammonium Hydroxide 
Figure 5.4 shows the liquid level rise in the ammonium hydroxide/glass particle experiment as a function of the change in sludge height. Also shown in this figure are the results for an analogous simulated waste consisting of glass beads and carbonated water $(120 \mathrm{~min}$. recirculation data of Figure 5.2). The differences in retention mechanisms for the two sludges are indistinguishable. Both data sets in the figure show an initial growth period in which bubbles grow without displacing particles (to a liquid level rise of $\sim 0.3 \mathrm{~cm}$ ), but the majority of retained gas is held in round and/or fracture bubbles that displace both the liquid and solid fractions. The mechanism of bubble retention is expected to be a function of sludge and liquid densities, the liquid-gas (bubble) surface tension, and other factors (Gauglitz et al. 1994). In the cases of water and ammonium hydroxide with glass beads, the effect of density differences in the liquids on gas retention behavior is negligible. The results shown in Figure 5.4 also suggest that surface tension differences between the ammonia and $\mathrm{CO}_{2}$ systems are also unimportant.

\subsection{Ammonia Gas with Chemical Simulant}

Gas retention studies were conducted in chemical simulant (SY1-SIM-91A) on both a sample containing only naturally occurring gas (dissolved and tiny bubbles) and a sample with added anhydrous ammonia. Figure 5.5 shows the liquid level rise (overall gas retention) as a function of vacuum pressure for the two simulant samples. The sample with added ammonia retained gas and gave a liquid level rise of $4.1 \mathrm{~cm}$ at a pressure of $4.2 \times 10^{4} \mathrm{~Pa}$ (17.5 in. $\mathrm{Hg}$ vacuum), whereas the unaltered simulant sludge only increased $0.7-0.8 \mathrm{~cm}$ at the same pressure. This indicates that the predominant mechanism of growth in the ammoniated sample was due to ammonia bubble retention. Gas release events were observed in the ammoniated simulant at lower pressures.

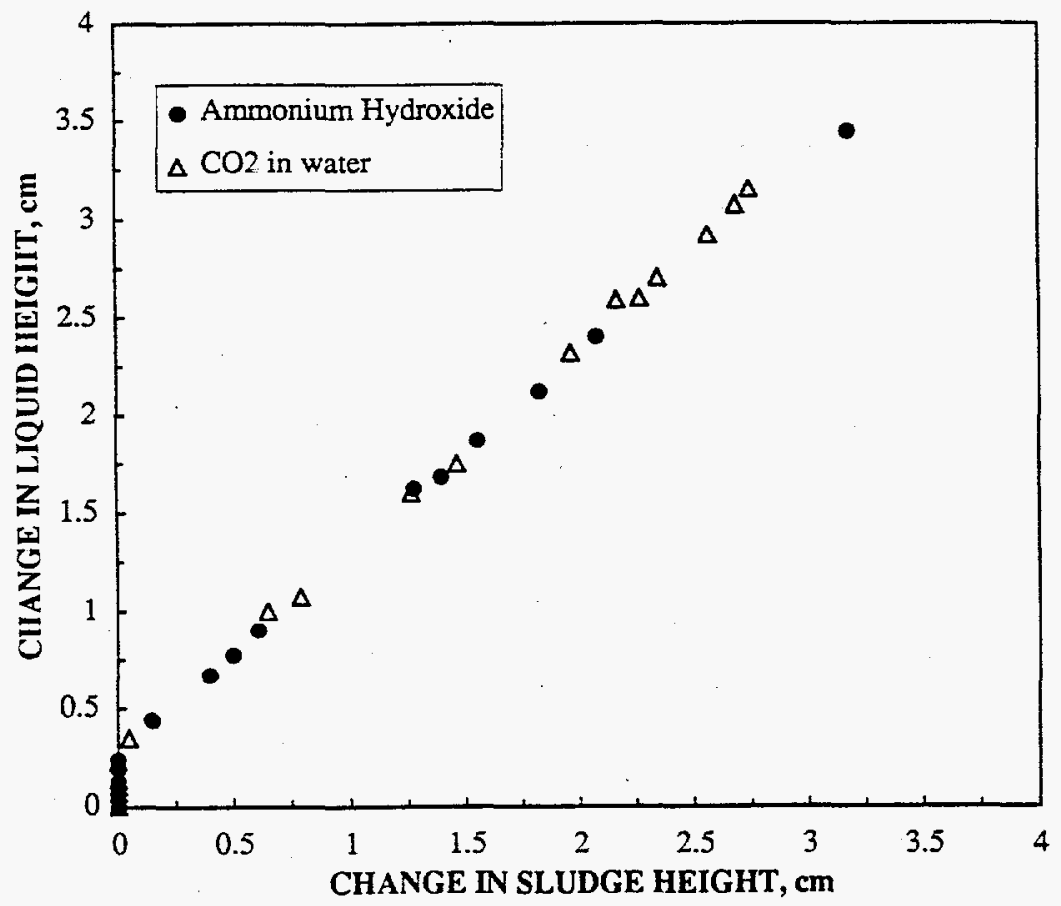

Figure 5.4. Comparison of Apparent Bubble Retention Mechanism by Glass Particle/Ammonium Hydroxide and Glass Particle/Carbonated Water Simulated Wastes 


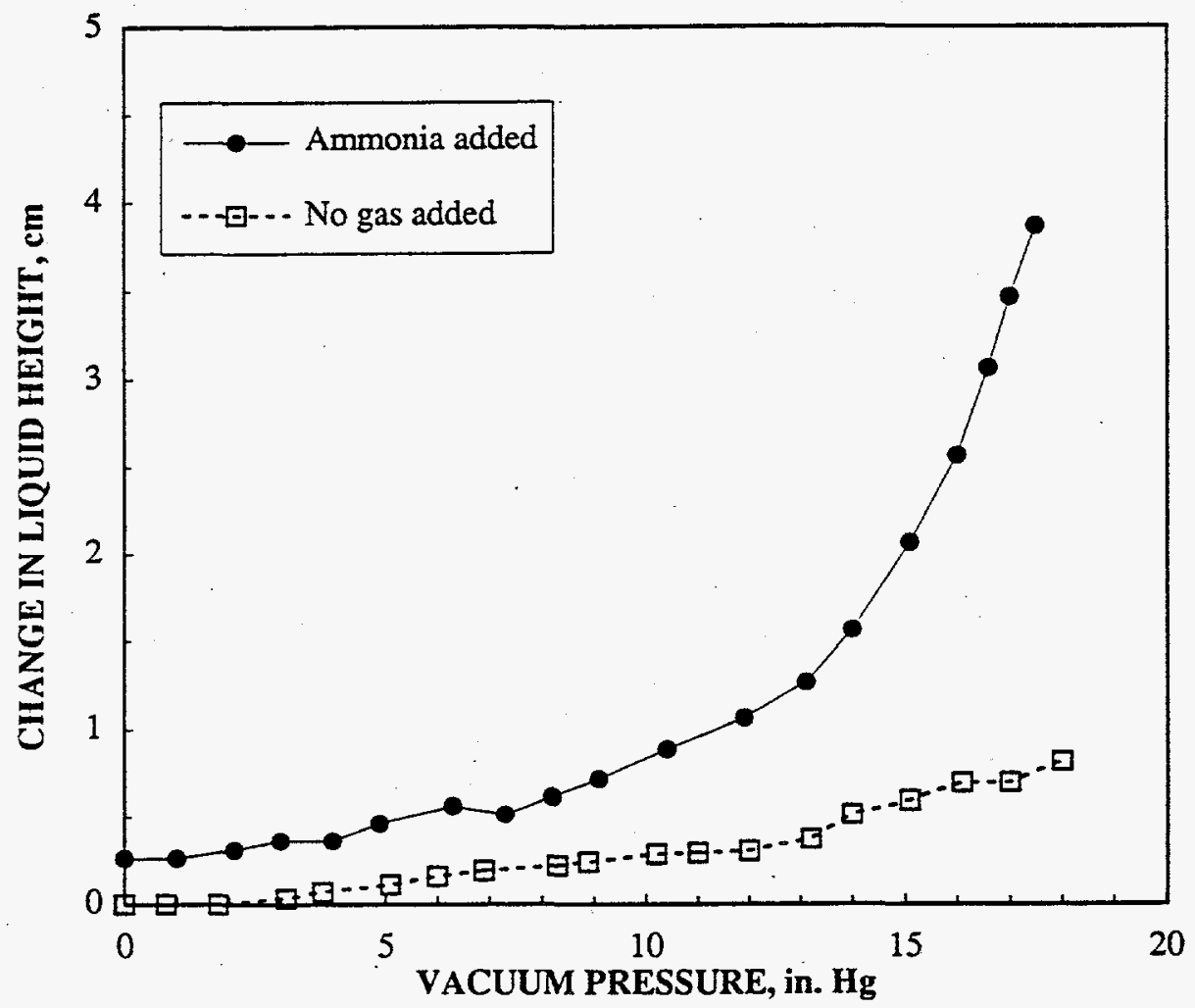

Figure 5.5. Effect of Added Ammonia Gas on the Overall Gas Retention in a SY1-SIM-91A Chemical Simulant Sludge

Figure 5.5 shows that some gas retention $(0.2-0.3 \mathrm{~cm}$ growth) occurred in the ammoniated sample following depressurization to atmospheric pressure ( 0 in. $\mathrm{Hg}$ vacuum) from the initial $\mathrm{NH}_{3}$ recirculation pressure of $1.7 \times 10^{5} \mathrm{~Pa}(10 \mathrm{psig})$. To attain more significant gas retention in the simulant without the aid of vacuum depressurization, higher ammonia pressures and/or longer recirculation times are necessary. The $\sim 240$-minute recirculation period used in the ammonia experiment was insufficient to achieve equilibrium between the anhydrous ammonia and the simulant sample. When recirculation was stopped, the ammonia supply cylinder closed, and the system isolated, the system pressure decreased $2.8 \times 10^{4} \mathrm{~Pa}(4 \mathrm{psi})$ in 18 minutes-suggesting that ammonia was continuing to be absorbed by the simulant. However, since sufficient ammonia was absorbed into the liquid to attain acceptable bubble growth with the enhancement of vacuum depressurization, it appears that the current operating conditions are reasonable, although not necessarily ideal.

Figure 5.6 compares the bubble retention behavior of the ammoniated chemical simulant with the glass particle/ammonium hydroxide simulated sludge. The mechanisms of retention in the two systems are somewhat different. As seen previously in the glass bead system, an initial liquid level growth to $0.3 \mathrm{~cm}$ occurred in which bubbles grew without displacing particles. After this dendritic growth phase, additional gas was retained predominantly as round and/or fracture bubbles which displaced both the liquid and solid fractions. Figure 5.6 shows that the transition between these two retention regimes occurred abruptly. In the ammoniated chemical simulant, the transition from dendritic to round/fracture bubble retention occurs gradually, as indicated by the slowly changing slope during the initial bubble growth. The variations in retention behavior are possibly due to differences in the pore size distribution 


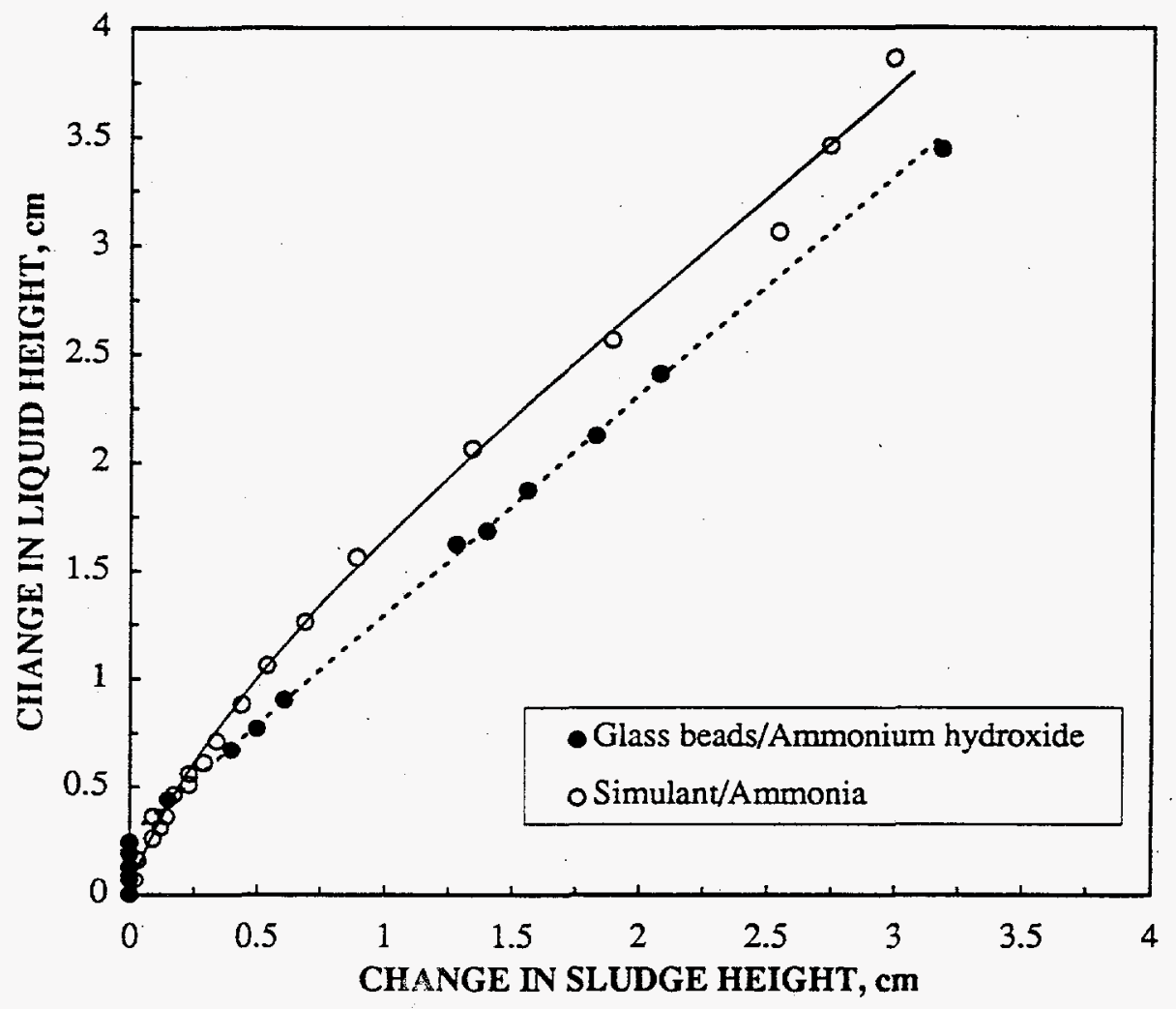

Figure 5.6. Comparison of Apparent Bubble Retention Mechanism by Glass Particle/Ammonium Hydroxide and SY1-SIM-91A Chemical Simulant/Ammonia Simulated Wastes

of the sludges. Visual observation of the chemical simulant sludge indicated that some large void spaces (regions of incompletely settled sludge) existed that allowed appreciable bubble growth without displacing the sludge solids. However, in more tightly settled areas, bubbles displaced solid particulate and liquid even in earlier stages of the gas retention experiment. The net effect of this broad pore-size distribution in the chemical simulant sludge is the continuous shift in the retention mechanism from dendritic-like retention to round bubble retention. Visual observation of retained and released bubbles showed that gas bubbles did not readily coalesce in the chemical simulant SY1-SIM-91A, presumably due to small particles armoring these bubbles. 


\subsection{Discussion and Future Work}

Three methods of varying complexity were used to measure bubble retention in simulated wastes. The amount of dissolved gas present and/or needed in the interstitial liquid to obtain significant bubble nucleation and growth determines the method to apply. The most involved approach requires that a gas be solubilized in the supernatant liquid under pressure while the fluid is recirculated, and then the system is depressurized under vacuum. The use of vacuum depressurization to enhance bubble nucleation and growth lowers the required gas pressure during the recirculation process and also minimizes the amount of gas that must be solubilized in the liquid to achieve suitable sludge growth. For marginally soluble gases (e.g., nitrous oxide), high gas pressure $\left(>1.5 \times 10^{6} \mathrm{~Pa}\right.$ estimated) requirements for simulant and real wastes are the limiting factor. For relatively soluble gases like ammonia, too much gas may dissolve into the liquid-and this may modify the sample chemistry. In the ammonia gas/chemical simulant experiment discussed in Section 5.3, for example, a liquid level rise of $0.6 \mathrm{~cm}$, equivalent to about a $3 \mathrm{~mL}$ volume increase in roughly $50 \mathrm{~mL}$ simulant, was detected in the retention column during the ammonia equilibration process. Although a considerable amount of ammonia dissolved into the sample, depressurization to atmospheric pressure resulted in only a $0.3 \mathrm{~cm}$ supernatant liquid level growth, more than an order of magnitude less bubble retention than desired. Vacuum depressurization was necessary when using ammonia as the soluble gas.

The approach of intermediate complexity also involves solubilizing a gas under pressure during fluid recirculation, but in this case depressurization to atmospheric pressure is sufficient to achieve the necessary slurry growth. Details of the experimental procedure for using the bubble retention apparatus shown in Figure 4.1 in this type of experiment are given in the appendix (Section A.1). This technique works well for gases of moderate solubility (e.g., $\mathrm{CO}_{2}$ in water) and is the basis of the proof-of-concept experiments described in Section 5.1. As noted previously, however, $\mathrm{CO}_{2}$ is not well-suited for real waste experiments owing to reaction of the gas with the alkaline waste.

The simplest approach to performing bubble retention experiments on sludges is to make use of existing dissolved gas in the sample. In this case, sludge growth is accomplished simply by evacuating the bubble retention column in a controlled manner. A procedure for performing such an experiment is outlined in the appendix (Section A.2). For this method to be successful, however, the sample liquid must contain sufficient dissolved gas to obtain the desired bubble growth as a result of dissolution upon evacuation. As shown in the data of Figure 5.4, this approach was used successfully with a slurry liquid of ammonium hydroxide and simulated sludge. In this experiment, vacuum pressures of $5.6 \times 10^{4} \mathrm{~Pa}$ (16.5 in. $\mathrm{Hg}$ absolute) resulted in rapid sludge growth and simulated gas release events. Alternatively, sample evacuation can lead to bubble generation as a result of supernatant liquid evaporation. In the retention experiment conducted with glass beads, water, and no added gas (see Figure 5.4), sludge growth is likely the result of a combination of the expansion of a small amount of dissolved air and some vaporization of the water at reduced pressure.

The relatively simple evacuation bubble retention experiments conducted on natural samples (no added gas) are particularly promising for the study of bubble retention in real waste. With the neat chemical simulant SY1-SIM-91A sludge, about $0.7 \mathrm{~cm}$ growth due to bubble retention was observed upon evacuation to $4.0 \times 10^{4} \mathrm{~Pa}$ (11.9 in. $\mathrm{Hg}$ absolute), as shown in Figure 5.6. Although this growth is five times less than desired in this apparatus, more retention could be readily achieved with a good vacuum pump/control assembly operated at still lower pressures. In real waste samples, sufficient naturally 
occurring gas may be more readily available than in chemical simulant by radiation-induced gas generation. This is the basis of bubble retention studies being conducted by P. R. Bredt. ${ }^{\text {(a) }}$ In his work, real waste samples and diluents are exposed to a radiation source at close range for 10 days or more to enhance gas generation, and bubble retention by the real waste at atmospheric pressure is monitored.

The evacuation bubble retention experimental approach described here coupled with gas generation accelerated by radiation appears to be a relatively simple, improved method for studying bubble retention behavior in real waste. The melding of the two existing techniques combines the advantages of both: gas generation by radiation dose closely mimics the natural process resulting in actual waste gases of concern; sample evacuation reduces the length of time per experiment and provides for greater slurry growth. A likely scenario is to expose the real waste sample to a radiation source for two days, rather than ten or more, and then immediately evacuate the sample to grow bubbles and monitor the gas retention behavior of the waste.

(a) A parallel study to the work presented here is being conducted by Paul Bredt (see footnote b, p. 2). 


\subsection{Conclusions}

Several of the underground storage tanks currently used to store waste at Hanford have been placed on the Flammable Gas Watch List because the waste is either known or suspected to generate, store, and episodically release flammable gases. And the episodic release of flammable gases from waste tanks is an important safety concern. To store the waste safely, retention of flammable gases must be minimized, and the conditions resulting in sudden releases of flammable gases in potentially hazardous quantities must be avoided. Very few laboratory data exist on the amount of gas a waste can retain. The work described in this report focuses on developing an apparatus for measuring the ability of simulated sludge to retain gas bubbles; progress has also been made toward developing an apparatus and method for measuring gas bubble retention in simulated sludge. The specific conclusions of this work are as follows:

- Dissolving soluble gases in the sludge liquid fraction followed by pressure reduction provides a suitable method of creating bubbles for measuring bubble retention in waste.

- Applying a vacuum to the sample with dissolved gas was a very effective and rapid method of nucleating and growing bubbles, particularly when the bubble nucleation did not occur at ambient pressure.

- Ammonia bubbles were successfully created in SY1-SIM-91A chemical simulant by applying a vacuum.

- The mechanism of bubble retention was also observed during these tests. For the sludges composed of glass beads, gas was observed to collect in both bubbles that fingered between the particles (dendritic bubbles) and bubbles that displaced the particles (both small round bubbles and large bubbles that fractured the sludge). In contrast, in the SY1-SIM-91A chemical simulant, only small round bubbles that displaced particles were observed.

- Gas bubbles did not readily coalesce in SY1-SIM-91A, presumably due to small particles armoring these bubbles.

\section{Recommendations for Future Studies}

Based on the success of this technique, we recommend that bubble retention measurements on real waste samples use the application of a vacuum to nucleate and grow bubbles following a dosage of radiation sufficient to create a small volume of gas. 



\subsection{References}

Allemann, R. T., Z. I. Antoniak, J. R. Friley, C. E. Haines, L. M. Liljegren, and S. Somasundaram. 1990a. Mechanistic Analysis of Double-Shell Tank Gas Release-Progress Report, November. PNL-7657, Pacific Northwest Laboratory, Richland, Washington.

Allemann, R. T., Z. I. Antoniak, J. R. Friley, C. E. Haines, L. M. Liljegren, and S. Somasundaram. 1990b. Collection and Analysis of Existing Data for Waste Tank Mechanistic Analysis-Progress Report, December. PNL-7658, Pacific Northwest Laboratory, Richland, Washington.

Allemann, R. T., Z. I. Antoniak, L. L. Eyler, and L. M. Liljegren. 1991. Conceptual Models for Waste Tank Mechanistic Analysis--Status Report, January. PNL-8011, Pacific Northwest Laboratory, Richland, Washington.

Allemann, R. T., T. M. Burke, D. A. Reynolds, and D. E. Simpson. 1993. Assessment of Gas Accumulation and Retention--Tank 241-SY-101. WHC-EP-0576, Westinghouse Hanford Company, Richland, Washington.

Bryan, S. A., L. R. Pederson, J. L. Ryan, R. D. Scheele, and J. M. Tinge. 1991. Slurry Growth, Gas Retention, and Flammable Gas Generation by Hanford Radioactive Waste Tanks. PNL-8169, Pacific Northwest Laboratory, Richland, Washington.

Bryan, S. A., L. R. Pederson, and R. D. Scheele. 1992. "Crust Growth and Gas Retention in Synthetic Hanford Waste.". Proceedings of Waste Management '92, pp. 829-834. Tucson, Arizona.

Bryan, S. A., L. R. Pederson, R. D. Scheele, and S. R. Adami. 1993. "Simulated Hanford Waste: A Study of Physical Properties, Gas Retention, and Gas Generation." Proceedings of High Level Radioactive Waste Management, pp. 1348-1354. Las Vegas, Nevada.

Bryan, S. A., and L. R. Pederson. 1994. Composition, Preparation, and Gas Generation Results from Simulated Wastes of Tank 241-SY-101. PNL-10075, Pacific Northwest Laboratory, Richland, Washington.

Gauglitz, P. A., L. A. Mahoney, D. P. Mendoza, and M. C. Miller. 1994. Mechanisms of Gas Bubble Retention. PNL-10120, Pacific Northwest Laboratory, Richland, Washington.

Hall, M. N. 1993. Tank 101-SY Hydrogen Mitigation by Low Frequency Vibration - Rheological Analysis and Feasibility Assessment. WHC-SD-WM-ER-164, Westinghouse Hanford Company, Richland, Washington.

Hudson, J. D., G. S. Barney, P. R. Bredt, A. R. Felmy, D. L. Herting, A. P. Larrick, D. A. Reynolds, C. W. Stewart, J. M. Tingey, and D. S. Trent. 1995. An Assessment of the Dilution Required to Mitigate Hanford Tank 241-SY-101. PNL-10417, Pacific Northwest Laboratory, Richland, Washington. 
Norton, J. D., and L. R. Pederson. 1994. Ammonia in Simulated Hanford Double-Shell Tank Wastes: Solubility and Effects on Surface Tension. PNL-10173, Pacific Northwest Laboratory, Richland, Washington.

Perry, J. H. 1950. Chemical Engineers' Handbook. McGraw-Hill, Inc., New York, p. 675.

Rieck, C. A. 1994. Conceptual Design Report: Initial Tank Retrieval Systems, Project W-211, February 1994. WHC-SD-W211-CDR-001, Westinghouse Hanford Company, Richland, Washington.

Stewart, C. W., L. A. Schienbein, J. D. Hudson, E. J. Eschbach, and D. L. Lessor. 1994. Assessment of Alternative Mitigation Concepts for Hanford Flammable Gas Tanks. PNL-10105, Pacific Northwest Laboratory, Richland, Washington.

Yaws, C., H-C. Yang, and X. Pan. November 1991. "Henry's Law Constants for 362 Organic Compounds in Water." Chemical Engineering, pp. 179-185. 
Appendix

Detailed Experimental Procedures 


\section{Appendix}

\section{Detailed Experimental Procedures}

\section{A.1 Addition of Partially Soluble Gas}

1) With retention column removed, fill pump and liquid feed lines with supernatant liquid from the supernatant liquid reservoir.

2) Place stainless steel frit and distribution plug in the bottom of the retention column and attach the bottom column cap with drain valve attached.

3) Add a slight excess of supernatant liquid (from a beaker) to the retention column through the open top with the drain valve closed; open the drain valve to fill pore spaces in the stainless steel frit, distribution plug, and cap and drain valve bodies with liquid.

4) Slowly add solid particulate or sludge to the supernatant liquid in the retention column, minimizing, as much as possible, entrainment of air bubbles in the settling sludge.

5) Attach top cap to retention column, aligning liquid feed tube 180 degrees from drain valve handle attached to bottom cap.

6) Connect retention column with fittings to recirculation and gas feed systems (three connections).

7) Open drain valve at bottom of column, switch liquid fill valve to draw from column instead of liquid reservoir, and turn on pump to recirculate at desired flow rate for several minutes; in this step, any remaining gas in liquid recirculation system should be cleared.

8) Purge the headspace over the liquid with the partially soluble gas of interest by turning pump off, switching liquid feed/gas purge valve to purge setting, and flowing soluble gas from source through gas inlet system (valves open) for approximately five minutes.

9) Switch the liquid feed/gas purge valve to the feed position and set the gas regulator to obtain the desired equilibrium gas pressure; the gas supply remains on throughout the gas/liquid equilibration step (10).

10) Turn the pump on and recirculate fluid at specified flow rate $(-2 \mathrm{~mL} / \mathrm{min}$. in this work) for desired period.

11) Isolate retention column from recirculation and gas supply systems by turning pump off, closing bottom drain valve and liquid feed/gas purge valve, closing gas inlet/exhaust valve, and turning off gas supply. 
12) Depressurize system at controlled rate with the micrometering exhaust valve and the gas inlet/exhaust valve (three-way); optionally, the system may be depressurized to subatmospheric pressures by connecting the exhaust line to a vacuum system.

13) Monitor bubble nucleation and growth throughout step (12).

\section{A.2 Naturally Existing Sample Gas}

The following procedure was developed for bubble retention studies using the existing recirculating fluid bubble retention apparatus. A simpler apparatus could be readily designed to accommodate the experimental approach of using naturally occurring sample gas for studying bubble retention in sludges.

1) Place stainless steel frit and distribution plug in the bottom of the retention column and attach the bottom column cap with drain valve attached.

2) Add a slight excess of supernatant liquid (from a beaker) to the retention column through the open top with the drain valve closed; open the drain valve to fill pore spaces in the stainless steel frit, distribution plug, and cap and drain valve bodies with liquid.

3) Slowly add solid particulate or sludge to the supernatant liquid in the retention column, minimizing, as much as possible, entrainment of air bubbles in the settling sludge.

4) Attach top cap to retention column, aligning liquid feed tube 180 degrees from drain valve handle attached to bottom cap.

5) Connect retention column with fittings to gas exhaust system (vacuum pump or reservoir) and plug the liquid feed line by attaching to closed feed/purge valve.

6) Depressurize system at controlled rate with control valves on the vacuum system.

7) Monitor bubble nucleation and growth throughout step (6). 


\section{Distribution}

No. of

Copies

Offsite

2 DOE Office of Scientific and Technical Information

4 Los Alamos National Laboratory

P.O. Box 1663

Los Alamos, NM 87545

Attn: J. R. White, K575

W. L. Kubic, K575

K. Pasamehmetlogu, K575

L. H. Sullivan, K557

W. R. Rossen

Dept. of Petroleum/Geosystems

Engineering

University of Texas at Austin

Austin, TX 78712-3246

Onsite

8 DOE Richland Operations Office

D. H. Alexander

S7-51

S. T. Burnum

R. F. Christensen

R. E. Gerton

J. M. Gray

C. A. Groendyke

Y. G. Noorani

G. W. Rosenwald

No of

Copies

22 Westinghouse Hanford Company

H. Babad

G. S. Barney

G. Galbraith
S7-30

S7-53

S7-54

S7-54

S7-54

S7-54

R3-77

S7-54

T5-12

H2-52
No. of

Copies

C. E. Hanson

D. L. Herting

J. O. Honeyman

J. D. Hopkins

G. D. Johnson

J. W. Lentsch (5)

J. M. Light

N. G. McDuffie

R. J. Parazin

D. A. Reynolds

C. A. Rieck

G. J. Rust

J. P. Sederburg

J. E. VanBeek

R. D. Wojtasek

H5-09

T6-09

S7-81

R2-11

S7-15

S7-15

B4-08

S7-15

H5-49

R2-11

R3-27

T4-01

R2-11

R3-27

S7-84

No of

Copies

34 Pacific Northwest Laboratory

J. M. Alzheimer

K5-22

W. J. Apley

S7-71

Z. I. Antoniak

K7-15

S. Q. Bennett

K7-90

P. R. Bredt

P7-25

K5-22

J. W. Brothers

P7-25

S. A. Bryan

J. L. Buelt

P7-41

P. A. Gauglitz (10)

P7-41

J. D. Hudson

K7-15

D. L. Lessor

F. E. Panisko

K7-15

P8-34

K2-44

L. R. Pederson

P7-35

S. D. Rassat (5)

P7-43

P. A. Scott

K7-15

C. W. Stewart

P7-25

J. M. Tingey

K7-15
D. S. Trent

Information Release (3) 